\title{
Detecting System of Collecting and Exhaustion of Chemical Gas in Tank Car
}

\author{
Qing $\mathrm{Li}^{1}$, Ligang Luo ${ }^{2}$, Yeqing Sun ${ }^{1}$ and Xinhua Xia ${ }^{2}$, Ge Shi ${ }^{1}$, Muda $\mathrm{Jin}^{2}$, Renyuan Tong ${ }^{1}$ and Zhipeng Zhao ${ }^{1, *}$ \\ ${ }^{1}$ College of Mechanical and Electrical Engineering, China Jiliang University, Hangzhou, Zhejiang, China \\ ${ }^{2}$ Zhejiang Provincial Special Equipment Inspection and Research Institute, Hangzhou, Zhejiang, China \\ ${ }^{*}$ Corresponding author
}

\begin{abstract}
In order to improve the progress of the tank car test , ensure inspector's personnel safety and save resources as well as reduce atmospheric pollution; This paper using a kind of explosion-proof valve which can be controlled by single-chip microcomputer to exhaust and collect the chemical gas in tank car. The system is mainly composed of the explosion-proof valve driver circuit, some airway, water sensors and a core controlling system. The mainly uses of core controlling is making the whole system to working by procedure and display status of each part. The system has been running in a special equipment inspection institute's tank car testing project, experimental results show that the system has a good performance and it can exhaust the harmful chemical gases and collect it in the tank car automatically, which improves the efficiency of tank trucks detection.
\end{abstract}

Keywords-tank car; collecting and exhaustion of chemical gas; driving of relief valve; integrated control system

\section{INTRODUCTION}

The tank of tank car which load chemical liquid, gas is a pressure vessel .According to the rules issued by the state administration of CHINA, tank cars must be tested periodically. At present, the existing detection needs inspector go into the tank cars.[1] If inspectors go into the tank while the harmful gas was not exhaust completely, it can cause serious damage to human body .And now, to exhaust the gas in tank usually by injecting water into the tanks, however, the overflow pipe of tanks are located in the top of tanks and the pipe was a $U$ structure. So, gas in the space which $30 \mathrm{~cm}$ high under the top of tank cannot be exhausted. To solve the disadvantage described above, it always pump the tank into a vacuum status and blow the tank repeatedly, which will make a waste of resource, pollute the atmosphere and reduce the efficiency of tank testing .

In order to, solve the disadvantage of present method of tank gas exhaustion. A new method was created in this paper, it can exhaust gas in tank and collect gas automatically by a system composed by explosion-proof valve, airway, water sensors, gas collecting tank and a core control system. In this paper, a human-computer interaction was designed to make the operation of inspector easily and monitor the running status of the whole system.

\section{OVERALL STRUCTURE OF SYSTEM}

This system main is mainly composed of explosion-proof valve, airway and gas collecting cans, water sensor and integrated control system. In the system, the first water sensor is information source of the explosion-proof valve which make it close or open. And the second water sensor is responsible for controlling the injection of water. The integrated control system takes charge of controlling switch of airways and monitor the status of the whole system. Over all structure is shown as figure I below.

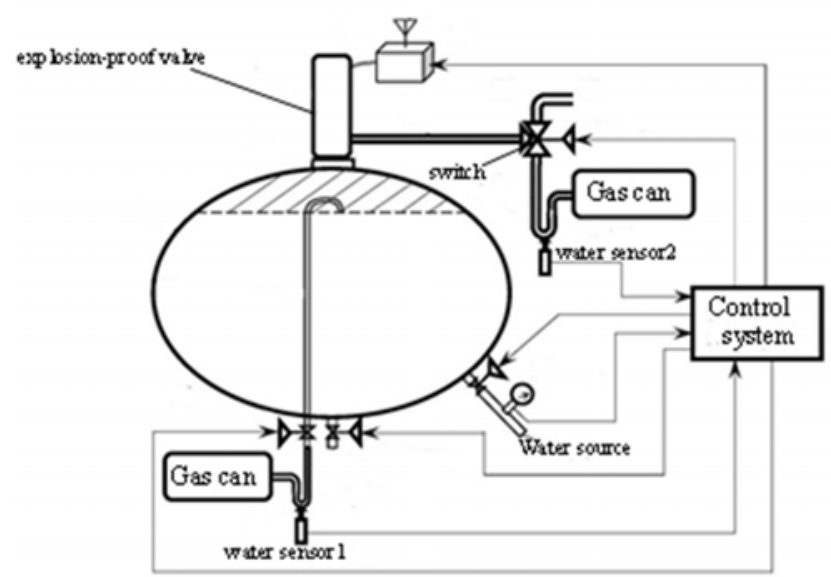

FIGURE I. OVERALL STRUCTURE OF SYSTEM

As shown in figure I, Firstly, the system has to ensure whether the initial value of water sensor is normal, the control system will turn on the water source switch to inject water. So chemical gas will flow into the gas can through the airway which like a J. Secondly, when water flow over the J type airway, there will be water hits water sensor1. So, control system will turn off the $\mathrm{J}$ type airway and turn on the explosion-proof valve at the same time. Gas will flow into gas can through the valve. Thirdly, when water hits the water sensor 2, It means that gas is exhaust and the control system should turn off the water source .Finally, inspectors should dismantle gas cans and drain away water by the software of system. The flowchart of system is shown as figure II. 


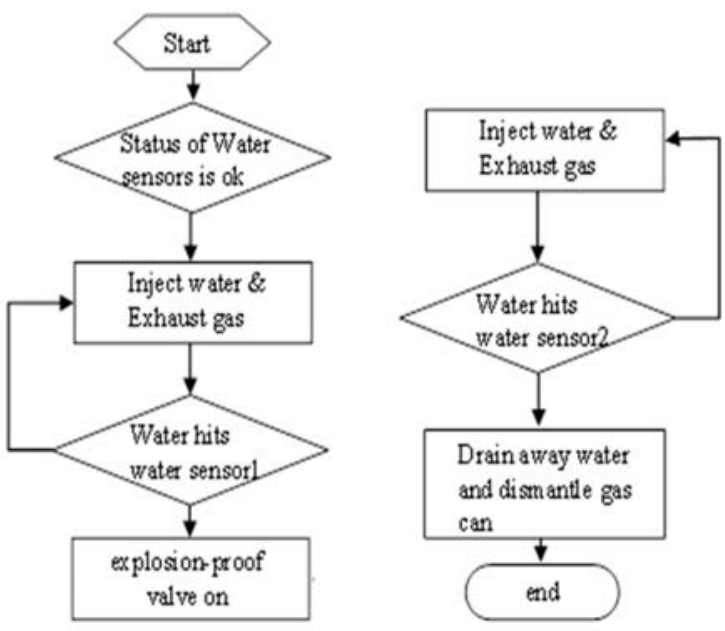

FIGURE II. WORKING FLOWCHART OF SYSTEM

The drive circuit of explosion-proof valve and the Collecting part of Control system are both compose by STM32 and external circuit. The drive circuit of explosion-proof valve mainly include MCU, stepper motor drive circuit. The control system is mainly consist of MCU, sensors and software.The two part of the whole system can exhaust and collect gas automatically.

\section{HARDWARE IMPLEMENTATION OF SYSTEM}

The system uses a high-performance ARM microcontroller STM32F103ZET6[3] to realize intelligent control and data processing, and it can communicate with software by its own serial port.

\section{A. The Relief Valve Control System Design}

In this paper, explosion-proof valve drive circuit is composed by MCU, stepper motor driver module and step motor. Open loop control mode is used in the system to realize the servo control of step motor. As figure III shown: stepping motor control system is composed of MCU, stepper motor driver module, the actuator (stepper motor). Stepper driver module mainly includes optical coupling isolation, pulse distribution, power driven.

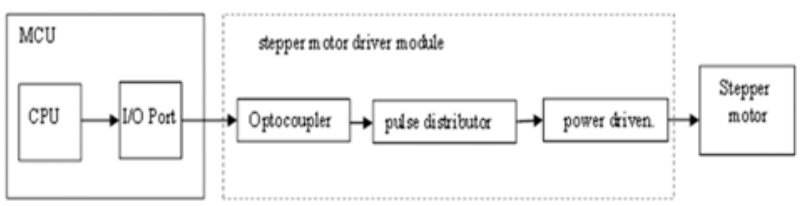

FIGURE III. STEPPING MOTOR CONTROL SYSTEM

The figure above is the overall structure of stepper motor control system, the system module realized the function under the cooperation of MCU, stepper motor driver module and stepper motor. Pulse signal in driven module which is the core of driven module. Pulse signal is produced by the logic part of MCU's CPU and be transmitted through the MCU IO port to the stepper motor driver module. Driven module according to the control signal received from MCU to product a kind of pulse signal that can be adjusted according to the requirements of stepper motor. Finally, the pulse signal needs amplifying by power driven module to drive the stepper motor.

\section{B. Stepper Motor Drive Circuit design}

AC power and DC power can't drive stepper motor due to the special character of stepper motor. To attain the normal working state of stepper motor special equipment is needed. Therefore ,L297 and L298N is used in the driven module to make the motor working. [2]

L297 is a chip was produced by Italian semiconductor company ,it can produce 4 control signal at the same time and drive a half bridge's or full-bridge's Pulse sequence distributor.L297 has 20 pins, as figure IV shows, it is mainly consist of a pulse distributor ,two PWM chopper and output control logic circuit. It has three working mode such as half step mode[4], basic step away from a phase excitatory mode and Basic step is apart from the two phase excitatory mode.

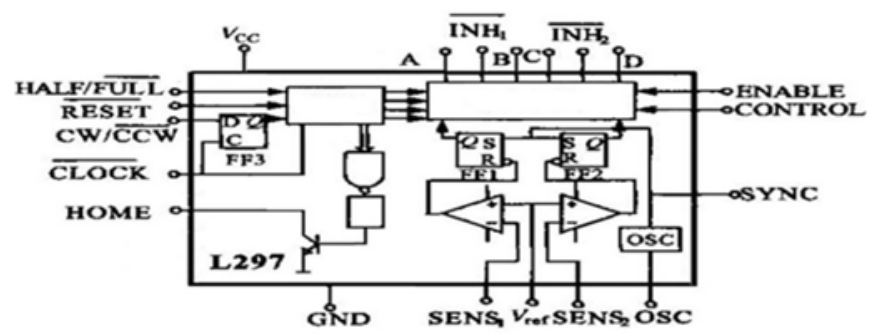

FIGURE IV. SCHEMATIC DIAGRAM OF L297 INTERIOR CIRCUIT

L298N is applicable to high voltage, large current motor driver and belongs to productions of ST, it depend on two independent of $\mathrm{H}$ full bridge driver. It is dedicated to bipolar stepper motor.L298N can accept criteria level signal. Schematic diagram of $\mathrm{L} 296 \mathrm{~N}$ interior circuit is shown as figure $\mathrm{V}$.

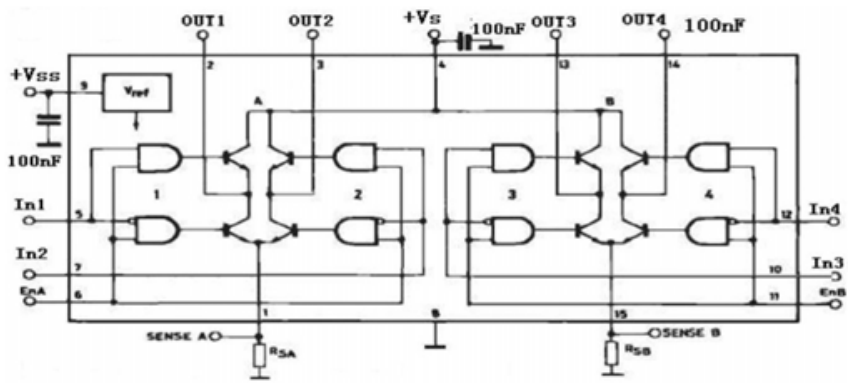

FIGURE V. SCHEMATIC DIAGRAM OF L298N INTERIOR CIRCUIT

The two kinds chips above are suitable for two phase bipolar and unipolar four phase stepper motor either. When the STM32 assigned direction and clock signal, driver module will receive commands, L297 pulse distributor will generate excitatory phase sequence automatically. Signal that can drive stepper motor will be produced by L298N's power amplifier. The advantage of the cooperation of L298N and L297 is that has low assembly costs and high reliability. So, the driven circuit is easy to control and design. Figure VI is the circuit designed by reference the specification of L297 and L298N.[5] It adds some optocouplers to isolate signals for the security of $\mathrm{CPU}$, so, the reliability of the circuit is increased. 


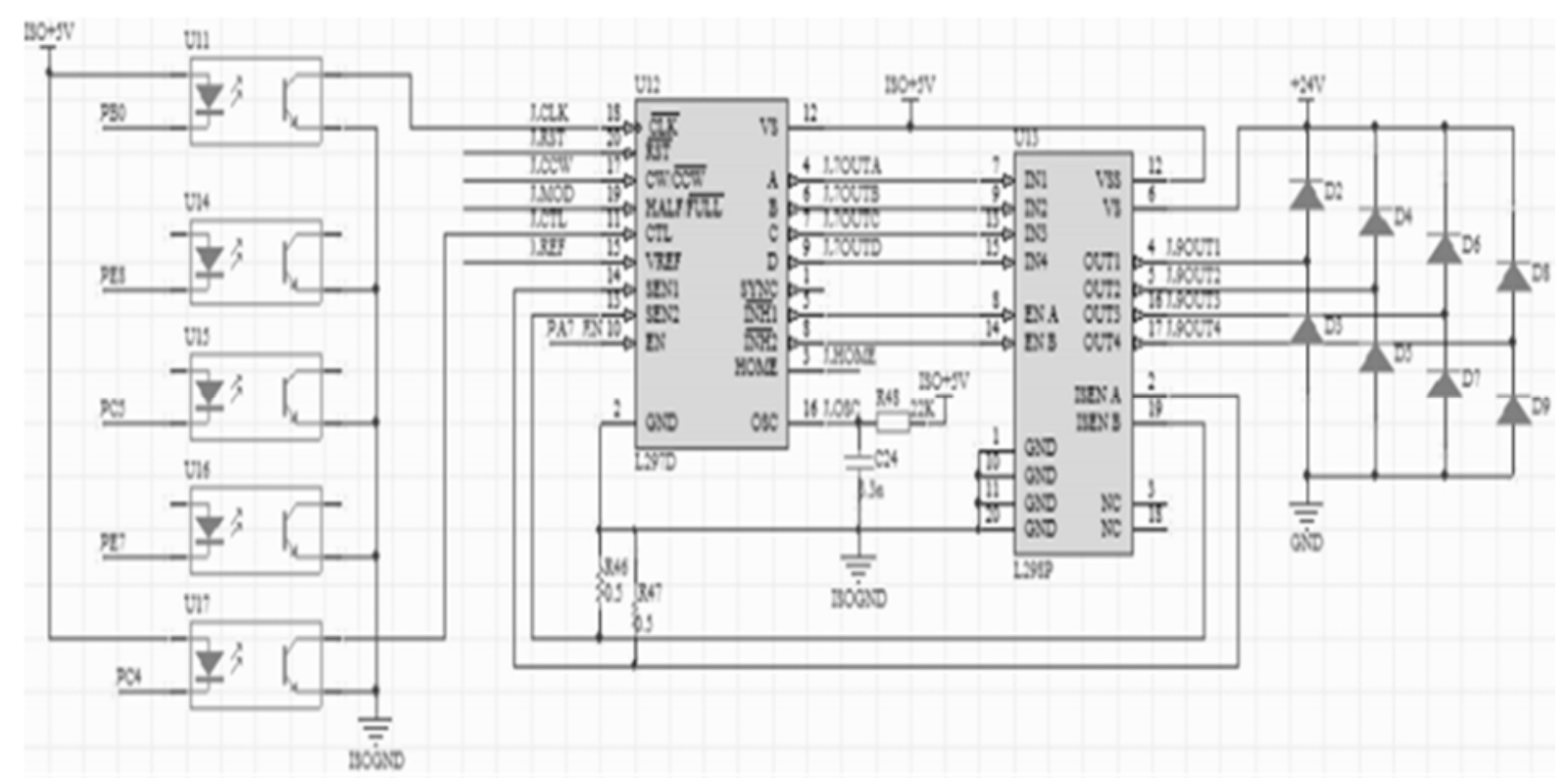

FIGURE VI. SCHEMATIC DIAGRAM OF MOTOR DRIVING MODULE

\section{SOFTWARE IMPLEMENTATION OF THE SYSTEM}

Software system uses the platform which was developed by Microsoft. Its name is C\#, an object-oriented programming language. It allows programmers to write various applications based on the MICROSOFT.net platform quickly, MICROSOFT. NET provides a series of tools and services to maximize the development and utilization of computing and communications. [6-7]

\section{A. Software Program Flow Diagram}

A kind of multi-threaded programming structure is working in this system. That means there is a child thread in the main thread. The main thread designed for initializing the interface, configuring serial-port and invoking child thread. Child thread can sample, process and send message to main thread. When application runs in a laptop, these two threads will work with each other to implement functions introduced above. The multi-threading main program flow chart was shown in Figure VII blow.

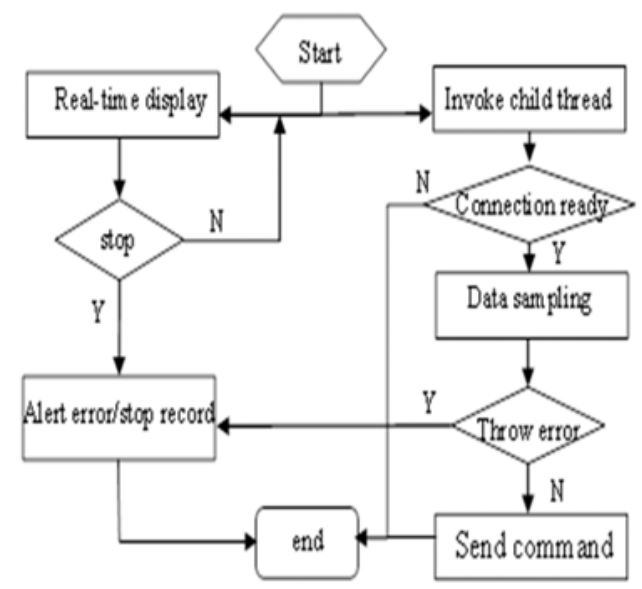

FIGURE VII. MULTI-THREADING FLOW CHART OF APPLICATION

\section{B. Monitoring System Display Interface}

Software interface of collecting and exhaustion of chemical gas in tank system is shown in Figure VIII. There are inspector's ID, tank car process diagram, plate number of tank car and daytime in the top of the interface. The application can map the relationship of those IDs and numbers. Below user Information section, working status of each part of the system is shown in the left. It can reflect something wrong with the system timely. In the middle of the software interface is the model of the tank, so, it is helpful to let inspectors to learn more the process of the system. Inspectors can operate the system by buttons in the right of the interface. Software interface of the system is shown in figure VIII.

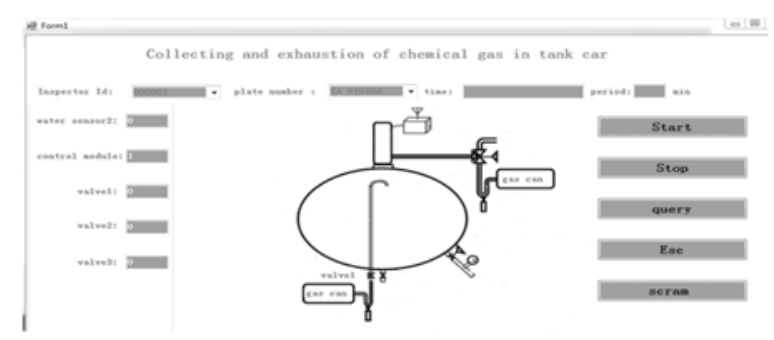

FIGURE VIII. SOFTWARE INTERFACE OF COLLECTING AND EXHAUSTION OF CHEMICAL GAS IN TANK SYSTEM

\section{SUMMARY}

In this system, single chip microcomputer receives water sensors signal through the integrated system, the control of the relief valve opening and mouth open, water injection valve control and monitoring the running state by wireless transmitting module to management server. The software of comprehensive control system is programed by C\#, it has good expansibility and friendly man-machine interface, it's easy to expand to other application fields of the tank car test. This tank car test system realizes the automatic exhaustion and collecting of harmful gas in the tank car and decreasing of test 
time. Through gas can, the harmful gas realization is recycled and the air pollution is reduced at the same time.

\section{ACKNOWLEDGMENT}

This work is funded by1, science and technology planning project of state Administration for Quality Supervision and Inspection and Quarantine(Project number:2014QK198).2, Scientific research projects of Zhejiang province quality and technical supervision system(Project number:20160225).

\section{REFERENCES}

[1] Tan Demiao, Liu Jianshu, Development and Design of LP Gas Tank Vehicles[J], process equipment \& piping,2001,38(2):37-41.

[2] Wen Xian-shi. Design of intelligent monitor based on ARM CortexM3[D]. Xihua University,2010.

[3] ST Microelecronics. STM32F103X User Manual. 2008.

[4] J. D. Wale, C. Pollock. Hybrid stepping motors and drives[J]. Power engineering journal, 2001, 15(1): 5-12.

[5] CAI Jing-jing,QIAN Shan-zhu,YAN Shuang-hong. Design of stepping motor servo controller based on single-chip computer[J]. Journal of Inner Mongolia Agricultural University(Natural Science Edition) , 2012, 33(4): 153-156

[6] Tang Guodong, Gao Yunguo. Single chip control of a steping motor based on L297/L298 chip [J]. Electric Machines \& Control Apllication. 2006, 22(34): 134-136.

[7] ZHANG Zhan-li, KANG Chun-hua, GUO Shi-jun, FU Ke-li. Control System of step-Motor Based on Micrcontriller unit[J]. ELECTRIC MACHINES \& CONTROL APPLICATION, 2011, 38(3): 28-31, 50 